\title{
Effect of Variable-Density and Constant-Density Representations of Flow on Simulating Terrestrial Groundwater Discharge into a Coastal Lagoon
}

\author{
Wissam Al-Taliby ${ }^{1 *}$, Hadeel Dekhn² \\ 1 Department of Environmental Engineering, College of Engineering, University of Babylon, Babylon 51001, \\ Iraq \\ 2 Ministry of Construction, Housing, Municipalities and Public Works, Soil Investigation Section, \\ Construction Laboratories, Babylon 51001, Iraq \\ * Corresponding author's e-mail: waltaliby2011@my.fit.edu
}

\begin{abstract}
Terrestrial groundwater discharge (TGWD) can be an important pathway for pollutants into coastal water bodies. Thus, a reliable way to quantify it is essential for efficient coastal management practices. This study evaluated the feasibility of using constant-density models for estimating TGWD amounts into the Indian River Lagoon, which is a variable-density estuarine environment. Constant-density models were developed using MODFLOW, while variable-density models were developed using SEAWAT. The numerical models were calibrated to match the field measured head data under the lagoon. The amounts of TGWD into the IRL and hydraulic head distributions calculated by the two codes were compared over eight pairs of numerical experiments. Two of those numerical experiments used the calibrated model and field measured conditions, while the rest of them used modified versions of the calibrated models, including variable anisotropy ratio $k$, variable lagoon salinity $L_{S}$, and increased water table elevation by $5 \%$. The results showed that the constant-density model is fairly accurate in estimating TGWD and head distributions at the calibrated $k$ in the range of 1000-20,000 with an error not exceeding 9.4\% under the actual measured field conditions. Even when $L_{S}$ was assumed to increase to ocean salinity value of 1.0, a case that rarely occurs in IRL, the calibrated constant-density model's accuracy was not affected substantially. However, the constant-density model failed to represent the physics of the variable-density environment at $k$ values lower than 1000 , where the error exceeded $129 \%$. Generally, the accuracy of the constant-density model was found to increase substantially at lower $L_{S}$ and higher water table elevations.
\end{abstract}

Keywords: Indian River Lagoon, terrestrial groundwater discharge, variable-density, constant-density

\section{INTRODUCTION}

Elevated concentrations of dissolved solids in groundwater that occurs in saline environments generate spatial density gradients that affect the groundwater flow patterns. Those density effects introduce additional complexity to the mathematical and numerical simulation of variable-density groundwater flow compared to constant-density systems [Paniconi et al., 2001]. Submarine groundwater discharge (SGD) [Langevin, 2003; $\mathrm{Li}$ et al., 2009] and saltwater intrusion [Lu et al., 2021; Roy and Datta, 2020; Ding et al., 2014;
Chang and Clement, 2018; Lin et al., 2009] are examples of such variable-density flow conditions. SGD is comprised of multiple components; terrestrial groundwater discharge (TGWD), which originates from fresh groundwater recharge that penetrates the aquifer, constitutes one of the most important SGD components as it represents a pathway of land-based pollutants. Numerical modeling of those flow regimes, where flow physics are driven by fluid density, typically incorporates the equations of flow and transport to represent the association between fluid density and salt concentration. SEAWAT [Guo and Langevin, 
2002; Langevin et al., 2003; Langevin and Guo, 2006] is one of the numerical codes developed by the U.S. Geological Survey (USGS) for solving the equations of variable-density flow and mass transport by coupling MODFLOW 2000 [Harbaugh et al., 2000] and MT3DMS [Zheng and Wang, 1999]. In the situations where density gradients are small or negligible, a constant-density flow model using MODFLOW may be sufficient to simulate the groundwater flow.

Obviously, variable-density models are more efficient and precise in representing the flow conditions in saline environments compared to constant-density models. However, constant-density scheme may also be a considerable option that groundwater modelers and water resources managers may opt to utilize for modeling variabledensity flow systems for several reasons. Extended computational time associated with running variable-density models is probably one of those reasons especially for complex computer models and in the situations where quick and preliminary decision making is needed as well as when high accuracy is not necessary. In such situations, eliminating some key physics for producing faster results may be justifiable. Furthermore, a wide range of geological and physical parameters is usually required for developing and calibrating variable-density models, such as diffusion coefficients and dispersivity, which are rarely available from the field. Therefore, the use of estimated values of those parameters elevates the level of inaccuracy and uncertainty of the model.

Several previous studies have compared constant-density to variable-density solutions of groundwater flow in different large-scale and laboratory-scale saline environments. It was found that constant-density solutions produced similar results to variable-density solutions under certain variable-density conditions. For Instance, Henry problem [Henry, 1964], which is a well-known saltwater intrusion problem, was solved by [Simpson and Clement, 2003] using variable-density and constant density schemes. It was found that constant-density solutions produced quite similar salinity distributions to those obtained by variable-density solutions when the recharge rate was doubled. They also concluded that constant-density solutions failed in producing reliable results under transient conditions. In another investigation that involved Henry problem, [Dentz et al., 2006] also found that constant-density models produced similar results to those obtained from variable-density solution at higher recharge rates. Constant-density and variable-density solutions of Henry problem conducted by [Al-Taliby and Pandit, 2017] also revealed that anisotropy ratio and freshwater recharge are amongst the most critical parameters that effect the matching between the two solutions. In another investigation, [Arlai and Koch, 2009] compared the two solution schemes in a two-dimensional coastal aquifer of $1000 \mathrm{~m}$ by $100 \mathrm{~m}$ and they concluded that the predicted Ghyben-Herzberg interface was closely simulated by the variable-density solution and not the constant-density solution. A vertical plane model of a hypothetical coastal aquifer which is larger in domain but similar in boundary condition to Henry problem was developed by [Motz and Sedighi, 2013] and solved by the variabledensity method using SEAWAT and constantdensity using MODFLOW. Hydraulic heads and fluxes simulated by MODFLOW were found to be comparable to those simulated by SEAWAT on the model's freshwater boundary.

On the basis of the previously described literature, the fluid density gradients in variabledensity environments are mostly affected by two parameters: the regional freshwater component rechartering the aquifer, and the hydraulic conductivity anisotropy $k$. Thus, these two parameters are expected to govern the degree of discrepancy between variable-density and constant-density solutions. Furthermore, groundwater salinity is also expected to play a significant role in the density gradients and subsequently, in the accuracy of constant-density solutions.

In this research, the variable-density and constant-density solutions were obtained from calibrated numerical models of a surficial coastal aquifer beneath the Indian River Lagoon (IRL), Florida. The constant-density models were developed using MODFLOW, while the variable-density models were developed using SEAWAT. The models of SEAWAT and MODFLOW were calibrated with similar hydraulic conductivity distribution and the following results were compared and investigated: i) hydraulic head distribution below IRL and ii) amount of TGWD into the IRL. The above-mentioned results were compared under three different modeling conditions including: hydraulic conductivity anisotropy $k$, IRL salinity $L_{s}$, and aquifer water table elevation.

The outcomes of this research deliver some key guidelines to groundwater modelers regarding the worthiness of using constant-density 
models in solving the groundwater problems that involve the occurrence of saltwater in the flow system. The paper also presents a quantitative evaluation of the magnitude of error in calculating groundwater seepage using constant-density models in a saltwater environment.

\section{MATERIALS AND METHODS}

\section{Study site}

The site studied in the current investigation is the Indian River Lagoon (IRL) which is one of three main sublagoons including Banana River Lagoon and Mosquito Lagoon that together constitute the entire Indian River Lagoon System (IRLS) as seen in Figure 1. This estuarine system, which stretches over about $251 \mathrm{~km}$ on the Atlantic coast of Florida, is shallow with its average depth not exceeding $2 \mathrm{~m}$. Due to its connectivity to the ocean through natural inlets, the lagoon water is brackish (Fig.1). The IRLS is surrounded by the Barrier Island from the east coastline and the Mainland from the west. The aquifer under the lagoon is unconfined with sand and shells, sandy clay, and clayey geological units. The surficial aquifer is separated from the underlying confined aquifer by marl and clay impervious formation known as Hawthorn formation [Brown et al., 1962]. Within the $3575 \mathrm{~km}^{2}$ [Martin et al., 2007] IRLS watershed shown in Figure 1, groundwater seepage into the lagoon comes mainly from the Mainland, while the Barrier Island contributes much lower seepage owing to its narrow area. As shown in Figure 1, the selected study transect is located across the IRL at Brevard County. The transect is directed perpendicular to the lagoon shoreline passing through the Mainland, the IRL, the Barrier Island, and eventually to the coastline.

\section{Field data collection setup}

In order to conduct data collection and model development, several single and clusters of onshore and offshore observation wells and piezometers made of PVC pipes were driven into the aquifer along the selected transect, as shown in Figures 2 and 3.

Several existing surface water points were utilized in addition to the installed observation wells to locate the groundwater divide on the Mainland side. The water table elevations were measured at

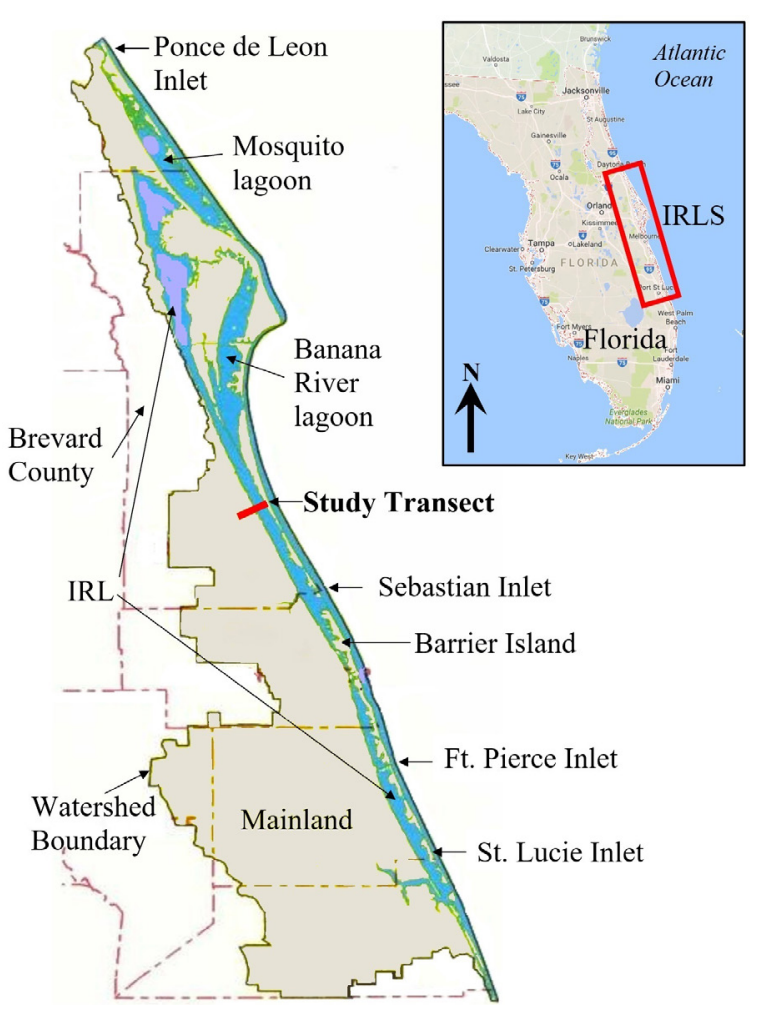

Figure 1. A map of the study area and the location of study transect

those points and wells, and maps of groundwater contours of the surficial aquifer were developed using kriging interpolation (Figure 3). The transect was then located to extend from the established groundwater divide to the ocean. The lagoon bed depth was measured from the west shore to east shore at several locations and the bed shape was established as shown in Figure 4. Clusters of deep and shallow monitoring piezometers were installed at several stations across the transect for collecting groundwater head and salinity measurements under the IRL (Figure 2). The vertical distribution and depths of those observation piezometers are illustrated in Figure 4.

In this research, field data was collected over two different sampling seasons: May and September. Each sampling season took one day to complete. On the day of any sampling season, data collecting included the measurement of groundwater piezometric head and salinity in the offshore stations, the lagoon surface water salinity, and water table elevations in the observation stations located on the Mainland and Barrier Island. The measured water table elevations on the mainland and Barrier Island were fitted into polynomial models of water table profiles to serve as terrestrial boundary conditions. All elevations were converted into National Geodetic Vertical Datum 


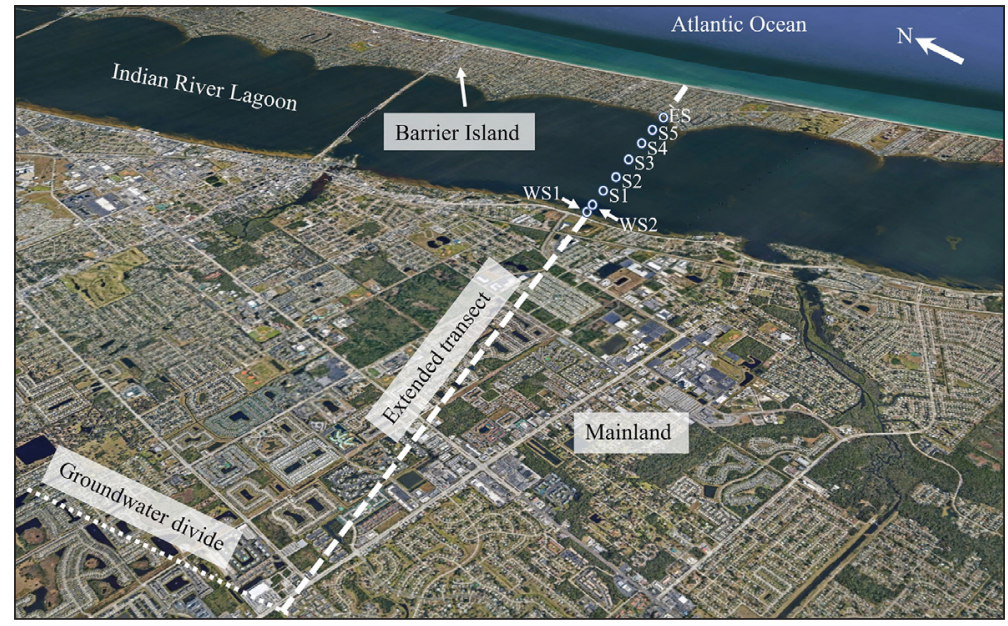

Figure 2. Extent of the transect and offshore observation stations

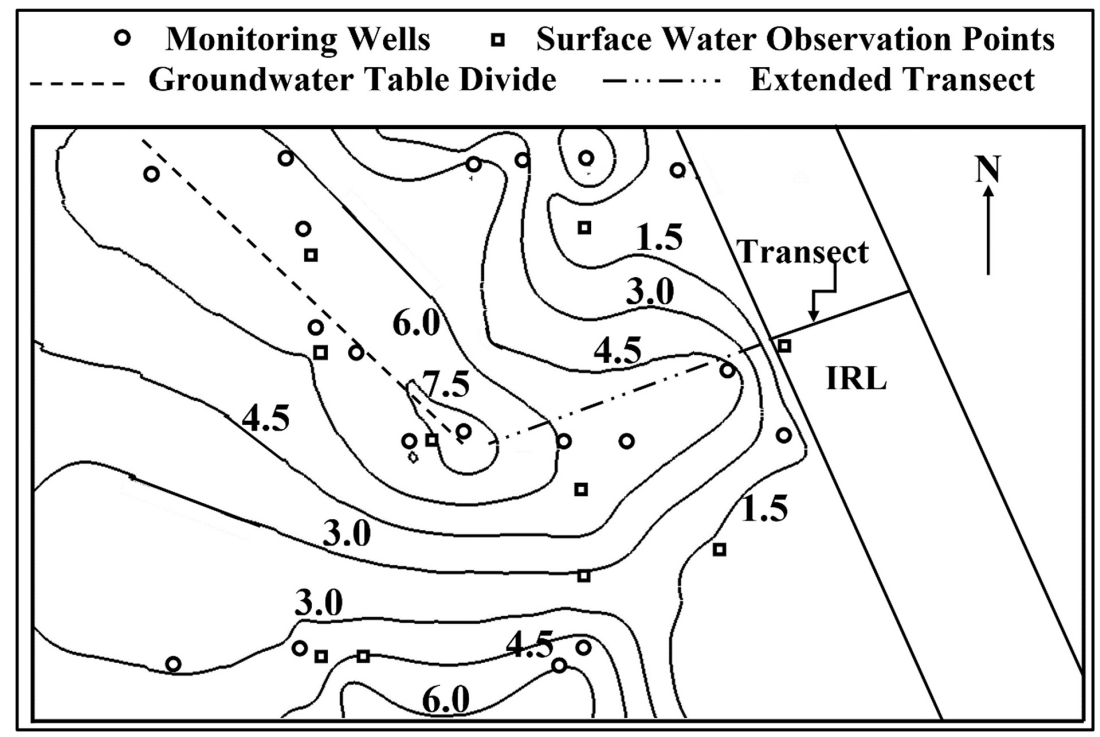

Figure 3. Monitoring locations and groundwater contours (in meter) on the Mainland showing the location of groundwater divide

of 1929 (NGVD29). The measured groundwater elevations at the groundwater divides and lagoon surface water elevation are given in Table 1.

\section{Numerical modeling}

Numerical models have been developed using SEAWAT and MODFLOW for the variabledensity and constant-density simulations, respectively. Finite difference grid and model domain dimensions are shown in Figure 5.

The model is comprised of a two-dimensional domain with a total horizontal distance of $9.74 \mathrm{~km}$ and a total depth of $33.5 \mathrm{~m}$ extending down to the confining Hawthorn formation. Finite difference mesh discretization is comprised of 22 layers and 76 columns. Columns vary in spacing from (15-300 $\mathrm{m})$ and layers are spaced at $(0.3-6 \mathrm{~m})$. Both SEAWAT and MODFLOW models are set with identical finite difference mesh discretization.

In terms of boundary conditions, and referring to Figure 5, the MODFLOW and SEAWAT models developed in this research simulated identical boundary conditions for all boundaries except saltwater boundaries (i.e. BC and DE). Constant head boundary type was assigned to boundaries $\mathrm{AB}$ and $\mathrm{CD}$ that represent terrestrial freshwater input into the model. The values of constant heads were obtained from the polynomial equations developed by statistical regression of the measured head data. The groundwater divide and Hawthorn boundary (AF and FE, respectively) were simulated as No-flow boundaries. In MODFLOW, 


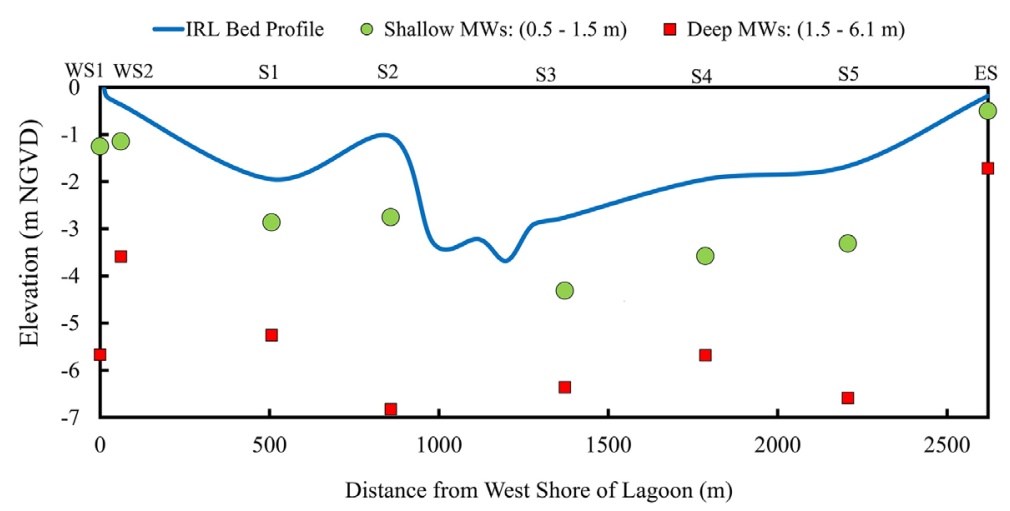

Figure 4. Transect bed shape and locations of shallow and deep observation wells

Table 1. Measured groundwater and IRL surface water elevations

\begin{tabular}{|l|c|c|c|}
\hline \multirow{2}{*}{$\begin{array}{c}\text { Sampling } \\
\text { season }\end{array}$} & \multicolumn{2}{|c|}{$\begin{array}{c}\text { Groundwater divide } \\
\text { (m NGVD29) }\end{array}$} & $\begin{array}{c}\text { IRL's water } \\
\text { surface }\end{array}$ \\
\cline { 2 - 3 } & Mainland & Barrier Island & (m NGVD29) \\
\hline May & 7.518 & 0.366 & 0.183 \\
\hline September & 8.829 & 0.591 & 0.576 \\
\hline
\end{tabular}

constant head values at saltwater boundaries BC and DE, which are IRL and the ocean, respectively, were in the form of equivalent freshwater hydraulic heads obtained from Eq. (1). Conversion of the measured hydraulic head values into equivalent freshwater head values was conducted in the constant-density model to account for density effects. However, SEAWAT automatically performs the conversion of measured heads into equivalent freshwater heads using the specified salt concentrations.

$$
h_{f w}=z+\left[\left(1+\left(\frac{\rho_{s}-\rho_{f}}{\rho_{f}}\right) C\right)\left(h_{s}-z\right)\right]
$$

where: $h_{f w}$ is equivalent freshwater hydraulic head,

$z$ is node elevation from the top of the Hawthorn boundary,

$\rho_{s}$ is density of saltwater,

$\rho_{f}$ is density of freshwater,

$h_{s}$ represents piezometric surface above Hawthorn boundary,

$C$ is the measured normalized salinity at the boundary.

Numerical models were calibrated to match the measured hydraulic heads observed in May and September below the lagoon (Figure 4). Horizontal hydraulic conductivity $K_{h}$ was estimated to be $30 \mathrm{~m} /$ day by applying Hazen equation [Hazen
1911] on the soil samples collected from the sediments. A summary of model input data used in this study is given in Table 2 .

The main calibration parameter was the vertical hydraulic conductivity $K_{V}$. Model calibration was accomplished by continuously adjusting zones and values of $K_{V}$ until a good match was achieved between the observed and modeled head values. The goodness of calibration was evaluated using three statistical measures, including: correlation coefficient, root mean square error (RMSE), and Nash-Sutcliffe Efficiency (NSE) index [Nash and Sutcliffe, 1970]. As shown in Figure 6 , a correlation coefficient of 0.97 , an RMSE of 0.091, and an NSE of 0.925 are calculated from the calibration results. Those statistics indicate very good calibration.

The ultimate calibrated $K_{V}$ was in the range of 0.0015 to $0.03 \mathrm{~m} /$ day. The majority of model domain had a calibrated $K_{V}$ value of $0.015 \mathrm{~m} /$ day. The corresponding calibrated anisotropy ratio ranged from 1000-20,000 and the predominant value is 2000 . The exact calibrated $K_{V}$ distribution was also used in the constant-density MODFLOW model.

\section{Numerical experiments}

A total of eight pairs of numerical experiments were conducted using each of SEAWAT and MODFLOW. The results produced by MODFLOW were compared with those simulated by SEAWAT in each experiment. The details of these experiments are provided in Table 3.

In the first two experiments, the respective May and September boundary conditions and IRL salinity were used to run the models at the calibrated anisotropy ratio to compare the reliability constant-density model under real-world field conditions. Experiments 3 and 4 used the 


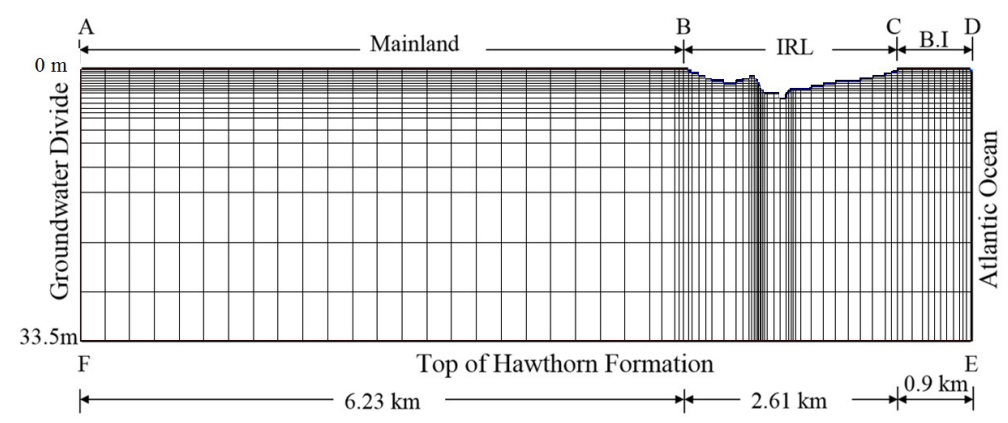

Figure 5. Finite difference grid of IRL models and domain dimensions

Table 2. Model parameters and input data used in the calibrated models

\begin{tabular}{|l|c|}
\hline \multicolumn{1}{|c|}{ Aquifer parameters } & Values \\
\hline Horizontal conductivity, $K_{h}(\mathrm{~m} /$ day $)$ & 30 \\
\hline Vertical conductivity, $K_{V}(\mathrm{~m} /$ day $)$ & 0.0015 to 0.03 \\
\hline Porosity, $n$ & 0.3 \\
\hline Specific storage, $S_{s}\left(\mathrm{~m}^{-1}\right)$ & 0.00001 \\
\hline Specific yield, $S_{y}$ & 0.01 \\
\hline Longitudinal dispersivity, $\alpha_{L}(\mathrm{~m})$ & 30 \\
\hline Transverse dispersivity, $\alpha_{T}(\mathrm{~m})$ & 3 \\
\hline Vertical dispersivity, $\alpha_{V}(\mathrm{~m})$ & 0.3 \\
\hline Molecular diffusion coefficient, $D_{m}\left(\mathrm{~m}^{2} / \mathrm{d}\right)$ & 0 \\
\hline Lagoon water normalized salinity, $S_{L}$ & Variable (Table 3) \\
\hline
\end{tabular}

exact May input data except that the IRL salinity was increased from 0.844 to 0.95 and 1 to study the effect of lagoon salinity on the results. The effect of anisotropy ratio was investigated in experiments 5,6 , and 7 by changing $k$ from the May calibrated conditions to $100,000,100$, and 10, respectively with keeping the other May conditions the same. Experiment 8 was conducted to study the effect of increasing freshwater recharge observed in May by $5 \%$.

\section{RESULTS AND DISCUSSION}

Inspecting the results given in Table 3, constant-density model simulated TGWD with $9.4 \%$ error compared to the values simulated by the variable-density model in experiment 1 . The accuracy of the constant-density model increased in experiment 2 by a factor of 3 with only $3.2 \%$ error because of the lower lagoon salinity (Table 3 ) and higher groundwater levels (Table 2). These results give the impression that constant-density models can replicate variable-density results to a reasonable level under real conditions especially under lower saline conditions and higher freshwater recharge. The groundwater head distributions predicted by constant-density and variable-density

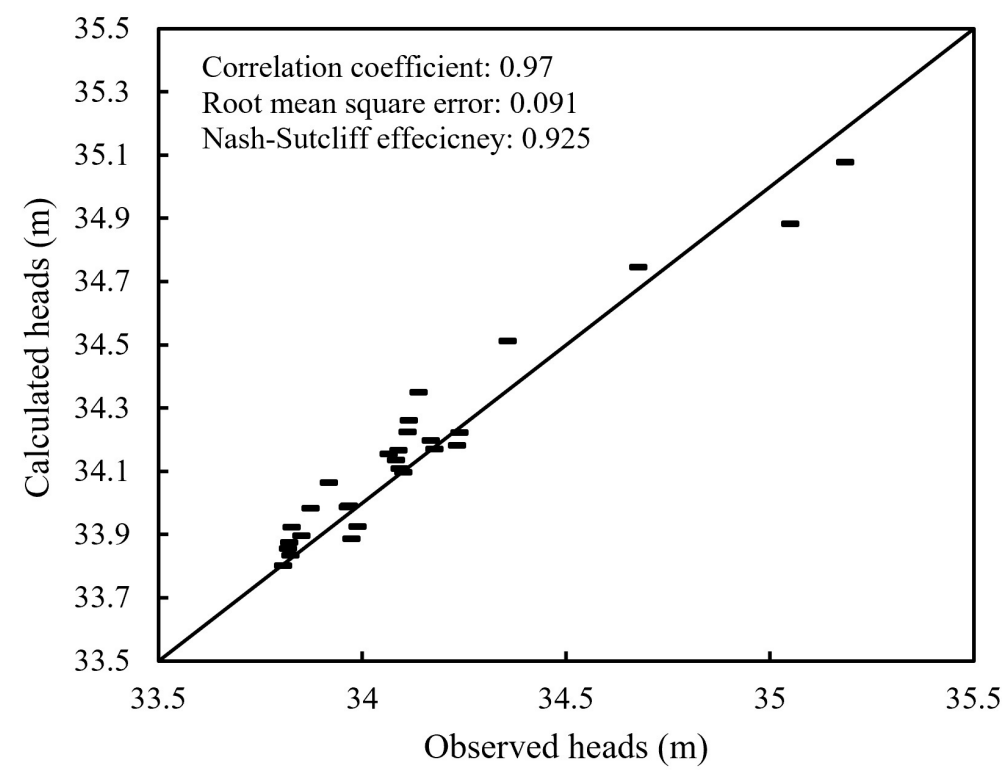

Figure 6. A scatter plot showing field head data observed in May and September versus SEAWAT simulated head values and statistics of calibration goodness 
Table 3. Conditions and results of numerical experiments

\begin{tabular}{|c|c|c|c|c|c|c|}
\hline \multirow{2}{*}{$\begin{array}{c}\text { Exp. } \\
\text { no. }\end{array}$} & \multirow{2}{*}{$\begin{array}{c}\text { Anisotropy ratio } \\
k\end{array}$} & \multirow{2}{*}{$\begin{array}{c}\mathrm{IRL} \\
\text { salinity } S_{L}\end{array}$} & \multirow{2}{*}{$\begin{array}{c}\text { Boundary } \\
\text { conditions }\end{array}$} & $\begin{array}{c}\text { TEAWAT } \\
\left(\mathrm{m}^{3} / \mathrm{day} / \mathrm{m}\right)\end{array}$ & $\begin{array}{c}\text { MODFLOW } \\
\left(\mathrm{m}^{3} / \mathrm{day} / \mathrm{m}\right)\end{array}$ & \multirow{2}{*}{ Error $(\%)$} \\
\hline 1 & $1000-20,000$ & 0.844 & May & $1.79 \times 10^{-4}$ & $1.96 \times 10^{-4}$ & 9.4 \\
\hline 2 & $1000-20,000$ & 0.306 & September & $1.82 \times 10^{-4}$ & $1.88 \times 10^{-4}$ & 3.2 \\
\hline 3 & $1000-20,000$ & 0.950 & May & $1.76 \times 10^{-4}$ & $1.95 \times 10^{-4}$ & 10.7 \\
\hline 4 & $1000-20,000$ & 1.000 & May & $1.75 \times 10^{-4}$ & $1.95 \times 10^{-4}$ & 11.3 \\
\hline 5 & 100,000 & 0.900 & May & $4.12 \times 10^{-5}$ & $4.34 \times 10^{-5}$ & 5.3 \\
\hline 6 & 100 & 0.900 & May & $2.59 \times 10^{-4}$ & $3.57 \times 10^{-4}$ & 38.2 \\
\hline 7 & 10 & 0.900 & May & $2.19 \times 10^{-4}$ & $5.02 \times 10^{-4}$ & 129.4 \\
\hline 8 & $1000-20,000$ & 0.844 & $(a)$ & $4.73 \times 10^{-4}$ & $4.95 \times 10^{-4}$ & 4.5 \\
\hline
\end{tabular}

models for experiments 1 and 2 are compared in Figures 7 and 8, respectively. The constant-density approach reproduced the head distribution calculated by variable-density model into a remarkable level. The effect of lower lagoon salinity and higher groundwater levels in experiment 2 in improving the accuracy can also be seen when Figure 8 is compared with Figure 7. The density effects are obvious in the simulated head distributions (Figures 7 and 8) on the ocean boundary.

Experiments 3 and 4 used the same $k$ distribution and boundary conditions as experiment 1 , except that lagoon salinity was increased to 0.95 in experiment 3 and 1.00 in experiment 4 . The results of these two pairs of numerical runs confirm that the discrepancy between constant-density and variable-density models in predicting the amount of TGWD into the lagoon increases with increasing lagoon salinity. However, increased IRL salinity does not seem to significantly affect the amount of TGWD predicted by either method.
This can be seen from Table 3 where TGWD predicted by SEAWAT in experiment 1 which is $1.79 \times 10^{-4} \mathrm{~m}^{3} /$ day $/ \mathrm{m}$ decreased very slightly to only $1.76 \times 10^{-4} \mathrm{~m}^{3} / \mathrm{day} / \mathrm{m}$ and $1.75 \times 10^{-4} \mathrm{~m}^{3} / \mathrm{day} / \mathrm{m}$ in experiments 3 and 4, respectively. The MODFLOW results of these two experiments showed similar behavior. It also can be seen that the amounts of TGWD predicted by either method are still lower than those simulated in experiment 2 of September sampling season. Thus, it can be inferred that the amounts of TGWD are governed by hydraulic gradient between the model boundaries and lagoon water level. It is also worth mentioning that increasing IRL salinity in experiments 3 and 4 did not produce much different head distributions from those presented in Figures 7 and 8.

Increasing $k$ value to 100,000 in experiment 5 compared to experiment 1 seems to reduce the error of MODFLOW prediction of TGWD to $5.3 \%$. However, decreasing $k$ to 100 and 10 in

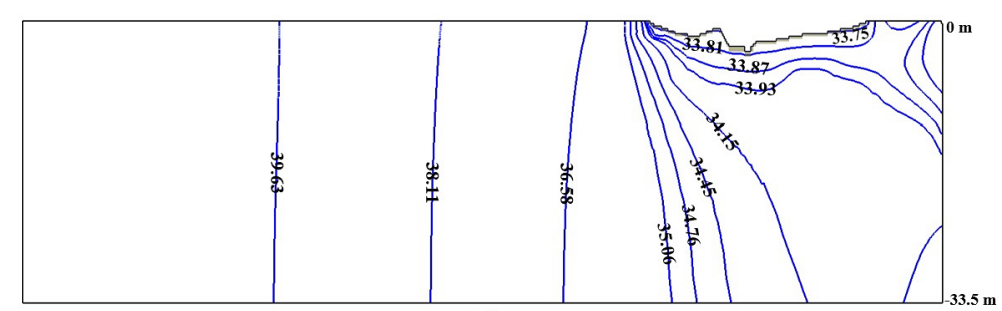

(a)

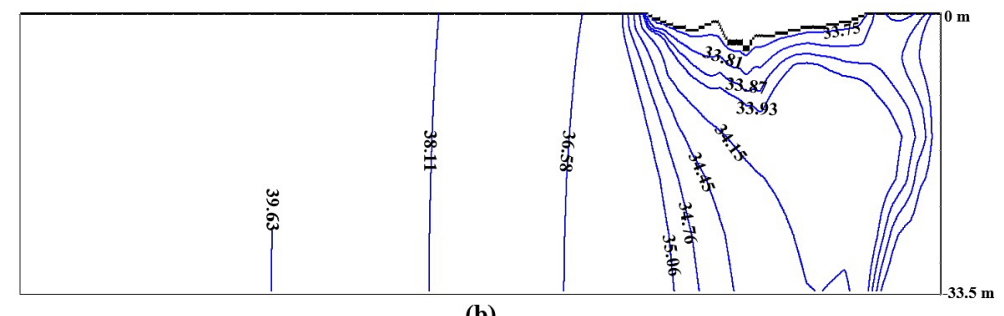

(b)

Figure 7. Groundwater head distributions simulated in experiment 1 using (a) constant-density MODFLOW and (b) variable-density SEAWAT 


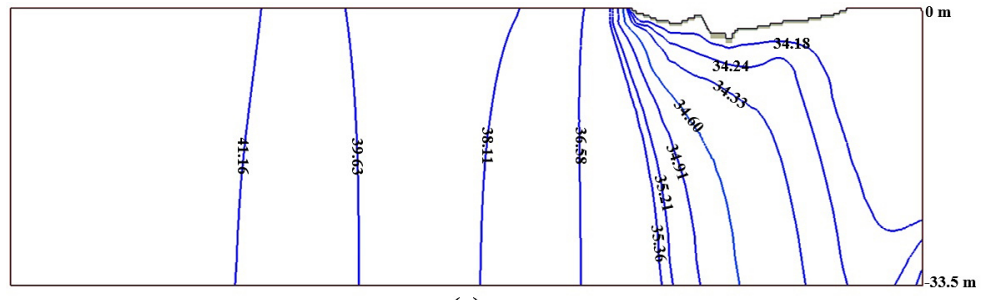

(a)

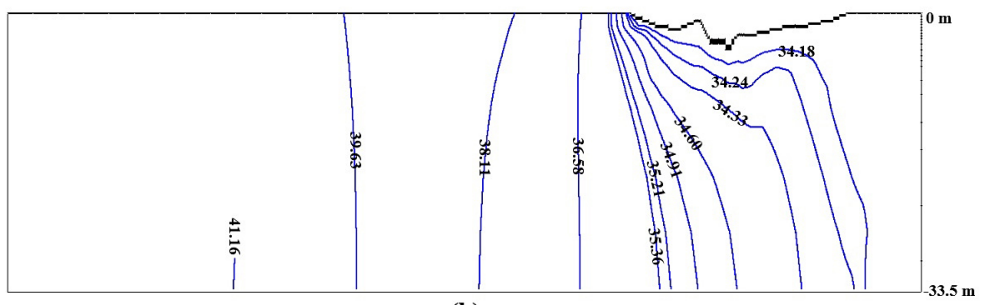

(b)

Figure 8. Groundwater head distributions simulated in experiment 2 using (a) constant-density MODFLOW and (b) variable-density SEAWAT

experiments 6 and 7, respectively, caused the error to significantly increase up to $129.4 \%$. This is because decreasing $k$ is equivalent to increasing $K_{V}$ which results in increased density effects due to the vertical encroachment of lagoon salinity into the aquifer and therefore, the density effects predominate over the advective forces. Figure 9 shows how MODFLOW fails to reproduce the hydraulic head distribution predicted by SEAWAT when $\mathrm{k}$ is increased to 100 .

The error of constant-density model in calculating TGWD is lowered to $4.5 \%$ which is equivalent to $50 \%$ improvement compared to experiment 1 when the groundwater levels were increased by just $5 \%$ in experiment 8 (Table 3 ). This improved accuracy of the constant-density model is also seen in the predicted head distributions shown in Figure 10.

Despite the wake of increasing computational abilities of modern high-speed computers, extended run times, especially for complex threedimensional groundwater models such as regional models have always represented a challenge. In this study, each of the numerical experiments ran in SEAWAT required 564 seconds to finish. However, it only required 0.07 seconds for MODFLOW to obtain the solutions. Running refined mesh experiments was also conducted in this research and it was found that constant-density models can run faster than variable-density models by a factor of 7000 and still produce similar results under moderately saline conditions.

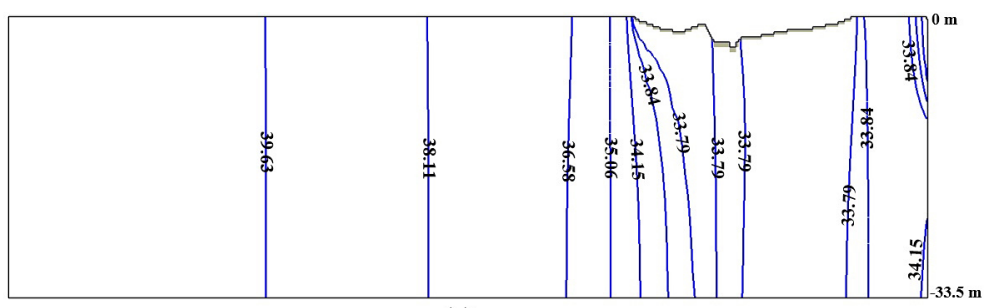

(a)

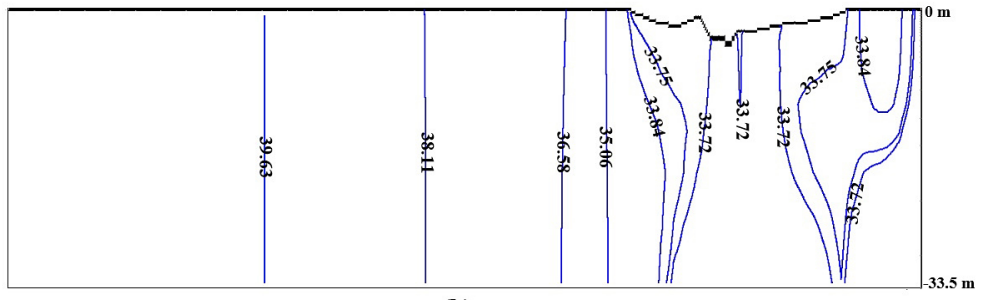

(b)

Figure 9. Groundwater head distributions simulated in experiment 6 using (a) constantdensity MODFLOW and (b) variable-density SEAWAT with $k=100$ 


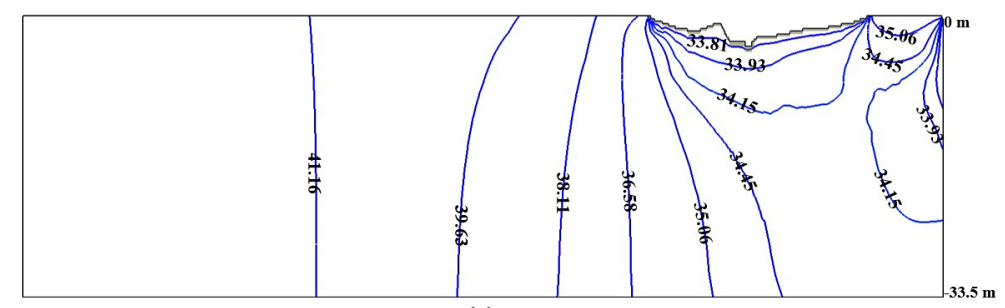

(a)

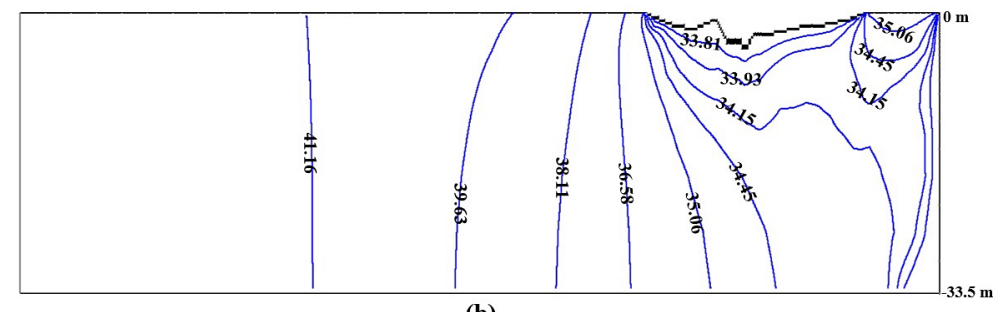

(b)

Figure 10. Groundwater head distributions simulated in experiment 8 using (a) constant-density MODFLOW and (b) variable-density SEAWAT with increased groundwater levels by 5\% compared to experiment 1

\section{CONCLUSIONS}

The results of this study showed that the use of constant-density models such as MODFLOW for modeling saline conditions like the IRL estuarine system can be satisfactory under field conditions of the estuary. Regardless of lagoon salinity and freshwater hydraulic gradient, the constantdensity model can approximate TGWD within 3 to 9 percent. The accuracy of constant-density models can increase significantly along with anisotropy ratio and advective forces driven by increased hydraulic gradient between the lagoon and water table. Even under low lagoon salinity and high groundwater gradient, constant-density model should be avoided if the anisotropy ratio is below 1000. Higher hydraulic gradient is the main driving force for higher amounts of TGWD reaching the lagoon. In terms of computational run time, the constant-density models used in this study seem to be faster than the variable-density models by a factor of 7000 while producing similar results under certain conditions.

\section{REFERENCES}

1. Al-Taliby W., Pandit A. 2017. Comparison of solutions of coupled and uncoupled models for the Henry problem. Proc. EWRI World Environmental \& Water Resources Congress, 89-102, California, USA.

2. Arlai P., Koch M. 2009. The importance of density-dependent flow and solute transport modeling to simulate seawater intrusion into a coastal aquifer system. Proc. International Symposium on Efficient
Groundwater Resources Management (IGS-TH 2009), Bangkok, Thailand.

3. Brown D.W., Kenner W.E., Crooks J.W., Foster J.B. 1962. Water resources of Brevard County, Florida. Report of Investigations 28, U.S. Geological Survey, Tallahassee, FL.

4. Chang S.W., Clement T.P. 2018. Perspectives on modeling saltwater intrusion processes in coastal groundwater aquifers. World Scientific Publishing Co, 73-109.

5. Dentz M., Tartakovsky D.M., Abarca E., Guadagnini A., Sánchez-Vila X. 2006. Variable-density flow in porous media. Journal of Fluid Mechanics, 561, 209-235.

6. Ding F., Yamashita T., Lee H.S., Pan J. 2014. A modelling study of seawater intrusion in the Liao Dong bay coastal plain, China. Journal of Marine Science and Technology, 22(2), 103-115.

7. Guo W., Langevin C.D. 2002. User's Guide to SEAWAT: A Computer Program for Simulation of ThreeDimensional Variable-Density Ground-Water Flow. Techniques of Water-Resources Investigations 6-A7, U.S. Geological Survey, Tallahassee, FL.

8. Harbaugh A.W., Banta E.R., Hill M.C., McDonald M.G. 2000. MODFLOW-2000, the U.S. Geological Survey Modular Ground-Water Model: User Guide to Modularization Concepts and the Ground-Water Flow Process. USGS Open-File Rep. 00-92, U.S. Geological Survey, Reston, Virginia.

9. Hazen A. 1911. Discussion: Dams on Sand foundations. Transactions of the American Society of Civil Engineers, 73, 199-203.

10. Henry H.R. 1964. Effects of dispersion on salt encroachment in coastal aquifers. Sea water in coastal aquifers. Geological Survey Water Supply Paper 1613C, U.S. Geological Survey, Washington, D.C., 70-84. 
11. Langevin C.D. 2003. Simulation of submarine ground water discharge to a marine estuary: Biscayne Bay, Florida. Groundwater, 41(6), 758-771.

12. Langevin C.D., Guo W. 2006. MODFLOW/MT3DMS-based simulation of variable density ground water flow and transport. Groundwater, 44(3), 339-351.

13. Langevin C.D., Shoemaker W.B., Guo W. 2003. MODFLOW-2000, the U.S. Geological Survey modular ground-water model: Documentation of the SEAWAT-2000 version with the variable-density flow processes (VDF) and the integrated MT3DMS Transport Processes (IMT). USGS Open-File Rep. 03-426, U.S. Geological Survey, Tallahassee, FL.

14. Li X., Hu B.X., Burnett W.C., Santos I.R., Chanton J.P. 2009. Submarine ground water discharge driven by tidal pumping in a heterogeneous aquifer. Groundwater 47(4), 558-568.

15. Lin J., Snodsmith J.B., Zheng C., Wu J. 2009. A modeling study of seawater intrusion in Alabama Gulf Coast, USA. Environmental Geology, 57, 119-130.

16. Lu P., Lin K., Xu C., Lan T., Liu Z., He Y. 2021. An integrated framework of input determination for ensemble forecasts of monthly estuarine saltwater intrusion. Journal of Hydrology, 598.

17. Martin J.B., Cable J.E., Smith C., Roy M., Cherrier J. 2007. Magnitudes of submarine groundwater discharge from marine and terrestrial sources:
Indian River Lagoon, Florida. Water Resources Research, 43(5), W05440.

18. Motz L., Sedighi A. 2013. Saltwater intrusion and recirculation of seawater at a coastal boundary. Journal of Hydrologic Engineering, 18(1), 10-18.

19. Nash J.E., Sutcliffe J.V. 1970. River flow forecasting through conceptual models part I - A discussion of principles. Journal of Hydrology, 10(3), 282-290.

20. Paniconi C., Khlaifi I., Lecca G., Giacomelli A., Tarhouni J. 2001. A modelling study of seawater intrusion in the Korba Coastal Plain, Tunisia. Physics and Chemistry of the Earth, Part B: Hydrology, Oceans and Atmosphere, 26(4), 345-351.

21. Roy D.K., Datta B. 2020. Saltwater intrusion prediction in coastal aquifers utilizing a weighted-average heterogeneous ensemble of prediction models based on Dempster-Shafer theory of evidence. Hydrological Sciences Journal, 65(9), 1555-1567.

22. Simpson M.J., Clement T.P. 2003. Theoretical analysis of the worthiness of Henry and Elder problems as benchmarks of density-dependent groundwater flow models. Advances in Water Resources, 26(1), 17-31.

23. Zheng C., Wang P. 1999. MT3DMS- a modular three-dimensional multispecies transport model for simulation of advection, dispersion, and chemical reaction of contaminants in ground-water systems: Documentation and user's guide. Jacksonville, Florida. Contact Report SERDP-99-1, U.S. Army Corps of Engineers. 